\title{
Problems of political and legal support for sustainable development of the hunting industry in Russia
}

\author{
Ivan Grebnev ${ }^{1,2, *}$ \\ ${ }^{1}$ Vyatka State University, Moskovskaya St., 36, 610000 Kirov, Russia \\ ${ }^{2}$ Vyatka State Agricultural Academy, Oktyabrskiy Prospect, 133, 610017 Kirov, Russia
}

\begin{abstract}
Hunting industry is a sphere of material production, a specific ecological and social phenomenon characterized by a variety of its functions from providing the population with high-quality food products to service functions. Political and legal documents adopted at the national level, defining the goal, objectives, principles, and main directions of the development of hunting natural resources, play the leading role in the development of the industry. Current acts of strategic planning and regulations lack the key point - a conscious choice of the type of hunting activity that meets the needs of society and the state at the present stage of historical development. Conceptual and legal uncertainty determines the consolidation in legal acts of mutually exclusive tasks for the development of the industry, declaring the need to simultaneously stimulate entrepreneurial activity and ensure the availability of hunting for citizens. The lack of recognition of the diversity of natural, geographical and cultural features of the hunting use of wild animals' resources, the lack of scenario-based forecasts and opportunities for adjusting goals are significant weak points of the current regulators. We believe that the development of strategic sectoral planning documents should take into account the right to hunt, securing the predominantly egalitarian nature of the hunting organization.
\end{abstract}

\section{Introduction}

The hunting industry of Russia is a traditional branch of nature management, which provides a solution to a complex of environmental and socio-economic problems and problems of the population and territories. In particular, the hunting economy plays a significant role in ensuring food and epizootic security, human health, ecosystem stability, managing populations of wildlife and eliminating threats from wild animals to life, health, human property, and other flora and fauna. In some territories, hunting is an important lifesupporting factor that has a significant impact on the household and cultural structure of local communities, including indigenous peoples. Hunting is becoming increasingly important in the service industry, primarily in tourism.

${ }^{*}$ Corresponding author: ia_grebnev@vyatsu.ru 
At the same time, hunting nature management as a sphere of application of human labor, functioning and development of the individual, society, territories, corporations and the state, has a number of structural problems which have a negative impact on its condition, implementation of tasks and the sustainable development potential. One of the most important reasons for the unsatisfactory state and development of this industry is the underdevelopment, inconsistency and formalism of conceptual legal acts and provisions in the system of public administration of the country's hunting economy. The purpose of the research is a systematic analysis of the provisions of federal political and legal acts in the field of hunting and the conservation of hunting resources, the identification of defects that impede the sustainable development of the hunting economy in Russia, and the development of proposals for improving public administration in this field.

\section{Materials and Methods}

The materials of the study were the set of provisions of the Strategy for the Development of the Hunting Economy in the Russian Federation until 2030, approved by the order of the Government of the Russian Federation No. 1216-r of 03.07.2014, federal regulations in the field of hunting and the conservation of hunting resources, and research works.

The work was carried out on the basis of a systematic approach using general scientific (dialectical method, method of comparative and systemic analysis, methods of generalization, classification and analogy) and special research methods (formal legal, comparative legal, technical legal, legal modeling) .

\section{Results and Discussion}

Regulations and political and legal acts are a means of formulating the legal policy of the state in a certain area of public administration, developed on the basis of an analysis of cultural and historical characteristics of the development of society and the state, social values, expectations and needs at the current stage of development. First of all, they have to ensure the modernization of relations in the respective communities and spheres of life, determine directions of the state development on the basis of a comprehensive assessment of the state of the industry and communities, to form strategies for solving current and future problems. The adoption of documents of a political and ideological nature by public authorities should increase the consistency and complexity of the impact on public relations in the relevant area.

Foreign authors widely discuss theoretical and practical problems of the implementation of public policies, strategies of hunting nature management $[1,2,3]$, questions about the place, role, meaning, functions of hunting in modern society $[4,5]$.

The regulatory framework for strategic planning in the Russian Federation is Federal Law No. 172-FZ of June 28, 2014 "On Strategic Planning in the Russian Federation" (hereinafter also - FZ No. 172). According to Federal Law No. 172, strategic planning is the activity of participants in strategic planning on goal-setting, forecasting, planning and programming the socio-economic development of the Russian Federation, constituent entities of the Russian Federation and municipalities, economic sectors and spheres of state and municipal administration, ensuring the national security of the Russian Federation, aimed to solve tasks of sustainable socio-economic development of the Russian Federation, constituent entities of the Russian Federation and municipalities and ensure the national security of the Russian Federation (Art. 3).

Our country is characterized by a wide practice of adopting legal acts of sectoral strategic planning. In the hunting industry the main document which determines the 
political and legal content of the hunting industry development is the Strategy for the Development of the Hunting Industry in the Russian Federation until 2030, approved by the order of the Government of the Russian Federation No. 1216-r of 03.07.2014 (hereinafter the Strategy). The Strategy provisions define priorities and main directions of state policy and legal regulation, targets, tasks and main measures for the long-term development of hunting in the Russian Federation, sustainable existence and sustainable use of hunting resource and preservation of their biological diversity.

The state policy in the field of hunting is reflected in the legislative acts that determine the current state of legal regulation in this area. The main regulators are the Federal Law No. 52-FZ "On the Animal World" of March 24, 1995 (hereinafter - FZ No. 52) and the Federal Law No. 209-FZ "On hunting and the conservation of hunting resources. and on amendments to certain legislative acts of the Russian Federation of July 24, 2009 (hereinafter also - Federal Law No. 209).

The substantive and regulatory analysis of the Strategy and Federal laws No. 52 and No. 209 as instruments of state influence on public relations makes it possible to single out a number of problems that have a negative impact on the quality of public administration of the hunting industry in Russia, sustainability of the existence and use of hunting resources.

Many hunting scientists and practitioners have a negative attitude to the current hunting legislation, primarily to the Federal Law No. 209 [6-9]. Letter No. 1/161 dated 05.06.2018 from All-Russian Research Institute of Hunting and Fur Breeding named after prof. B.M. Zhitkov expressed the attitude of the specialized scientific center to the Federal Law No. 209: "Unfortunately, there is only "patchwork" improvement of the Law on Hunting now, it has been amended 20 times. However, private changes and additions can't change its destructive essence".

Law enforcement practice is consistent with the "spirit" and content of regulators. M.N. Andreev, N.V. Kraev, V.N. Kraeva, having studied public administration in the field of hunting and conservation of hunting resources, come to the conclusion that "nowadays special state bodies are losing the status of a full-fledged body of state management of the industry, $<\ldots>$ their functions are concentrated on only one side of the problems of protection, reproduction and use of hunting resources - animals' preservation and reproduction, which actually becomes the goal of state policy, for the sake of which the regulation is carried out "[10].

Therefore, the Strategy for the Development of Hunting Economy in the Russian Federation until 2030 has been approved in order to improve legal regulation in the field of hunting and preserve hunting resources, in particular: adjustments to the Federal Law No. 209 adopted in 2009, and the law enforcement practice on its basis since 2014 .

The strategy is a part of the political and legal doctrine of Russia. It reflects and consolidates the concept of modernization of the hunting industry and the development of hunting legislation up to 2030, thereby providing a mechanism for public administration of the industry. This Strategy, adopted at the national level, is a political and legal document reflecting the characteristics of the state. It must proceed from an understanding of state views on the issues of motives, goals, forms, conditions, methods, technologies for the conservation and use of animal resources. It has to meet the expectations of society, which is necessary for the implementation of the national development goals. Accordingly, the strategic planning document must meet certain requirements, such as certainty, consistency, balance, attainability of the set targets and indicators. The document should present a projected and predicted model of the future state of the industry, describe its quantitative and qualitative parameters.

Having analyzed the text of the Strategy, we conclude that it does not meet the requirements for a number of reasons. So, the guiding basis of any conceptual legal act is a system of principles that consolidate the key principles, values and the desired legal state of 
the regulatory sphere. The Strategy provides the following principles: ensuring human rights to a healthy environment; managing hunting resources based on their monitoring data; maintaining a balance of economic, social and environmental interests of society and the state. These principles are general ecological and do not satisfy the requirements for the basic foundations of hunting strategic planning. The same claims are made to the basic principles of legal regulation in the field of hunting and the conservation of hunting resources, fixed in Art. 2 of the Federal Law No. 209, in which the hunting industry as an economic sector and a specific ecological and social phenomenon is reflected only as an activity to ensure the conservation of hunting resources and hunting production, which does not contribute to the sustainability of these processes. From our point of view, the principles of the Strategy should determine the importance of hunting as part of the cultural tradition of the multinational people of the Russian Federation, as a social value, its important place in the system of economic, cultural, environmental relations, its role in life support and solving the whole complex of problems at the present stage of historical development. It is important to proceed from the nature of the right to hunt. We believe that the predominantly egalitarian nature of the organization of hunting, the role of public associations of hunters should be consolidated. At the same time, it should be recognized that forms, types, timing, methods, objects and hunting tools are the choice of the society of the corresponding territory, they must be acceptable to society and integrated into the multisectoral nature management at the local level [11].

The absence of sectoral principles of hunting economic development also influences goal-setting, formation of tasks and directions of hunting management, causing inconsistency and inefficiency of the entire state policy. The goal of the Strategy is the provision of sustainable development of the hunting industry and the availability of hunting for citizens by increasing the number of animals while maintaining the sustainability of ecological systems. The presented formulation of the goal does not cause comments, however, the target component of any legal act should highlight a number of independent tasks as certain promising guidelines and the main directions of state policy, which, to a certain extent, should reflect interests and development priorities of the state and society in a particular area. Having studied the tasks fixed in the Strategy, main directions of state policy and indicators of the development of the industry, we come to the conclusion that the leading role in the document is assigned to the activities to preserve and increase the number of animals, to provide an opportunity to hunt them. These provisions are superficial and ill-considered, since their implementation does not meet interests of society and the state in hunting as a sphere of material production and a factor in the socio-cultural development. In addition, the Strategy contains a fundamental contradiction: it proclaims the need to simultaneously stimulate entrepreneurial activity, increase the estimated value of animals and hunting products, and ensure the availability of hunting for citizens. These tasks have mutually exclusive content. The development of entrepreneurial activity is a prerequisite for the formation of a set of commercially oriented hunting farms, their activities are based on using restrictive mechanisms to hunting in various forms and an increase in its value. Increasing the availability of hunting implies the cost of permits that are acceptable for most hunters, ensuring the possibility of hunting, granting hunters equal rights in the distribution of permits for scarce hunting species (demand exceeds the possible volume) and in the most demanded lands, granting a priority right to public associations of hunters, which reduces the investment attractiveness of the industry.

The key and qualitative drawback of the Strategy is the absence of a conscious choice of the type of hunting activity that meets the needs of society and the state at the present stage of historical development, and, accordingly, a vision of the future state of the industry by the time this strategic planning document expires. The choice in this case is between two opposite models of hunting - elite, considering hunting as a privilege of wealthy citizens, 
implemented mainly in Western Europe, and egalitarian, in which the right to hunt is realized regardless of the property status of citizens, realized mainly in North America [12 ]. We believe that the absence in the Strategy of a choice in favor of one or another model of hunting economy makes the remaining provisions empty and generally makes the adoption of the document meaningless, since many provisions can be implemented within the framework of other functions of the state (environmental, sanitary epidemiological, etc.).

Moreover, significant defects of the Strategy are the lack of recognition of the diversity of natural-geographical and cultural features of the hunting use of wild animals' resources, the lack of scenario-based forecasts and opportunities for adjusting goals.

\section{Conclusions}

Thus, the key role of political and legal documents is to determine ideological and organizational foundations for the development of the corresponding sector of the economy and the sphere of public administration. The strategy for the development of the hunting economy in the Russian Federation until 2030 in its form is a political and legal act designed to determine the priorities and content of the state hunting policy, programs for its implementation, targets and the desired state of the hunting economy by 2030 in the context of structural and institutional changes in the country's economy, a new stage in the technological development of the global economy. On the basis of the Strategy, the main directions of improving legislation in the field of hunting natural resources should be determined. However, this fundamental state document does not correspond to its purpose, which negatively affects the state of normative regulation and law enforcement practice, creating a threat to the sustainability of the protection and use of hunting resources.

\section{References}

1. M. Nie, State Wildlife Policy and Management, 64 (2004)

2. P. T. Fell, Environmental Politics, 17 (2008)

3. J. Hiedanpää, D.W. Bromley, Environmental Policy and Governance, 21 (2011)

4. C.A. Jacobson, D.J. Decker, Society and Natural Resources, 21 (2008)

5. A. Fischer et al., Journal of Environmental Planning and Management, 56 (2013)

6. V.G Safonov, Ecology, 5 (2013)

7. N.V. Kraev et al., Legislative support for the protection of animal world: monograph (2016)

8. E.V. Netsvetova, Humanitarian aspects of hunting and its management, 3 (2017)

9. I.A. Grebnev, Theoretical and applied ecology, 1 (2019)

10. M. N. Andreev, N. V. Kraev, V. N. Kraeva, State policy in the field of hunting and hunting economy: history and modernity: monograph (2013)

11. I.A. Grebnev, Humanitarian aspects of hunting and game management, 2 (2018)

12. S.P. Matveychuk, Modern problems of nature management, hunting and fur farming, $\mathbf{1}$ (2007) 